\title{
Myocardial Infarction Following Repair of a Ruptured Heart
}

\author{
hossein vakili ${ }^{1}$ and zhiva taherpour ${ }^{1}$ \\ ${ }^{1}$ Affiliation not available
}

December 2, 2020

\begin{abstract}
The patient was a 40-year-old man with penetrating chest trauma two days before being referred to our hospital.during first repair LAD artery was sutured.because of ongoing $\mathrm{CP}$, he was candidate for bypass surgery and revascularization .The surgeon had reported ligation of LADA by some sutures during previous cardiac repair.

Myocardial Infarction Following Repair of a Ruptured Heart

Hossein Vakili ${ }^{1}$, Zhiva Taherpour ${ }^{2 *}$

${ }^{1}$ Cardiovascular Disease Department, Shahid Beheshti University of Medical Sciences, Tehran, Iran

$2^{*}$ Cardiovascular Disease Department, Kermanshah University of Medical Sciences, Kermanshah, Iran.

\section{Clinical key message:}

Penetrating chest trauma can lead to cardiac rupture and coronary arteries damage, which causes a high mortality rate (1-4). Most of the patients with penetrating cardiac trauma die at the scene of the accident (3). Coronary artery (CA) injuries are rare but highly lethal (5). Also, CA injury may occur during repair of a ruptured heart as in our reported case.
\end{abstract}

\section{Key words:}

Chest trauma, Myocardial infarction, Coronary artery injury

\section{Clinical Feature:}

The patient was a 40-year-old man who suffered from penetrating chest trauma with left atrium and right ventricle injuries two days before being referred to our hospital following a street fight. He had undergone repair of cardiac tears at a hospital outside the city, by a general surgeon.

He was still complaining of chest pain after being transferred to the intensive care unit. In the first place, the pain caused by surgery was taken into account but after taking an electrocardiogram and seeing Q wave formation and ST-segment elevation in the antroseptal leads, he was referred to our center with suspicion of damage to the left anterior descending artery (LADA).

At the time of admission, his vital signs were stable. Echocardiography revealed akinesia in apical and antroapical and antroseptal walls with global left ventricular ejection fraction (LVEF) about $30 \%$. Coronary angiography was done and LADA was cut off at mid part. We decided to try angioplasty by crossing a 0.014 " wire but any attempt failed (fig1). Assuming that the artery was ligated during heart repair by sutures and due to the fact that the patient was stable and three days had passed since his heart attack, we decided to follow the patient. He was discharged in good general condition after three weeks.

Two months later, he complained of chest pain in functional class II. Echocardiography revealed LVEF about $50 \%$. Coronary angiography was performed and showed LADA with good distal run off after previous site of 
occlusion (fig2). Therefore, the patient was a candidate for bypass surgery and revascularization of LADA was performed with harvested LIMA, successfully. The surgeon had reported ligation of LADA by some sutures during previous cardiac repair. After a week he was discharged in good condition.

\section{Discussion}

Penetrating chest trauma and myocardial contusion can lead to cardiac rupture, which cause high mortality rate (1-4). Most of the patients with cardiac trauma die at the site of the accident.

Coronary artery injury is uncommon usually considered deadly (6).

Due to its location, LADA is the most commonly injured coronary artery (7).

Our case report shows that heart injury might be complex, even in follow up. And any emergency repair might have consequences, such as ligating of a coronary artery by sutures, especially in non-equipped facilities.

\section{Acknowledgment}

The authors have acknowledged from Department of Cardiology ,Modarres Hospital, Shahid Beheshti University of Medical Sciences, Tehran, Iran.

\section{Conflict of interest}

None declared.

\section{Authors contribution}

Zh. T. is corresponding author; H. V. and Zh. T. diagnosed and followed the patient and conceived of the case report, and took full responsibility for the contents of this manuscript.

\section{References}

1 - Campbell, N. C., S. R. Thomson, D. J. Muckart, C. M. Meumann I. Van Middelkoop and J. B. Botha (1997). "Review of 1198 cases of penetrating cardiac trauma." Br J Surg 84 (12): 1737-1740.

2 - Lassus, J., I. Tulikoura, Y. T. Konttinen and S. Santavirta (2001). "Myocardial contusion as a cause of delayed cardiac rupture. A case report." Injury 32 (10): 789-793.

3 - Salehian, O., K. Teoh and A. Mulji (2003). "Blunt and penetrating cardiac trauma: a review." Can J Cardiol 19 (9): 1054-1059.

4 - Vohra, H. A., S. Chaudhry, C. M. R. Satur, M. Heber, R. Butler and P. D. Ridley (2006). "Sutureless off-pump repair of post-infarction left ventricular free wall rupture." Journal of Cardiothoracic Surgery 1 (1): 11.

5 - Atkins, B. Z., J. P. Salomone, A. Subramanian, J. R. Burke and G. A. Vercruysse (2010). "Management of Traumatic Coronary Artery Injuries: Advantages of Off-Pump Coronary Artery Bypass." European Journal of Trauma and Emergency Surgery 36 (4): 380-384.

6 - Demetriades, D. and B. W. Vander veen (1983). "Penetrating Injuries of the Heart: Experience over Two Years in South Africa." Journal of Trauma and Acute Care Surgery 23 (12): 1030-1041.

7 - Santavy, P., A. Steriovsky and V. Lonsky (2015). "Delayed revascularization following complete transection of left anterior descending artery after a stab wound." International Journal of Surgery Case Reports 6 : 241-243. 

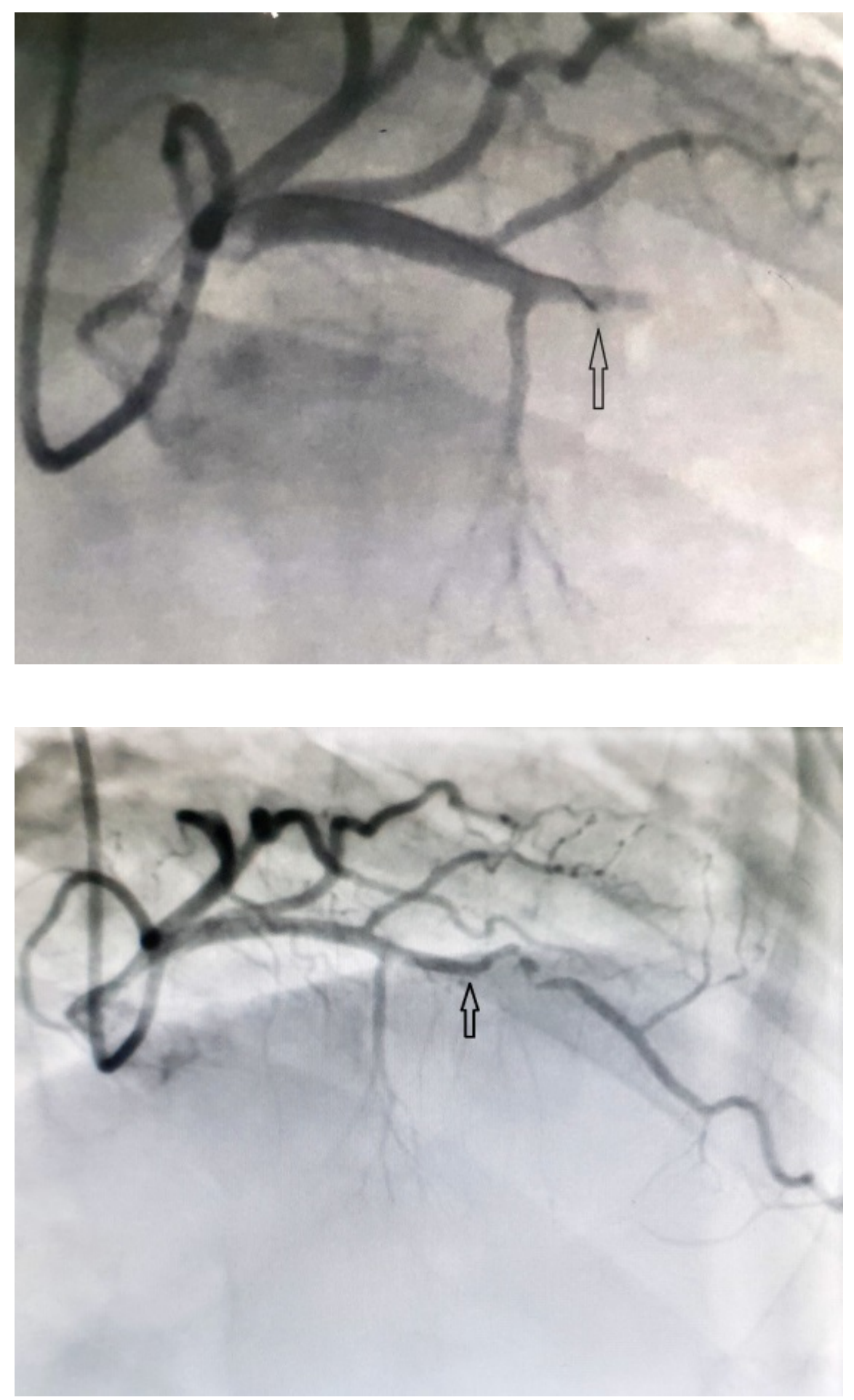

Fig1 - coronary angiography at admission day fig2 - coronary angiography after 2 months 

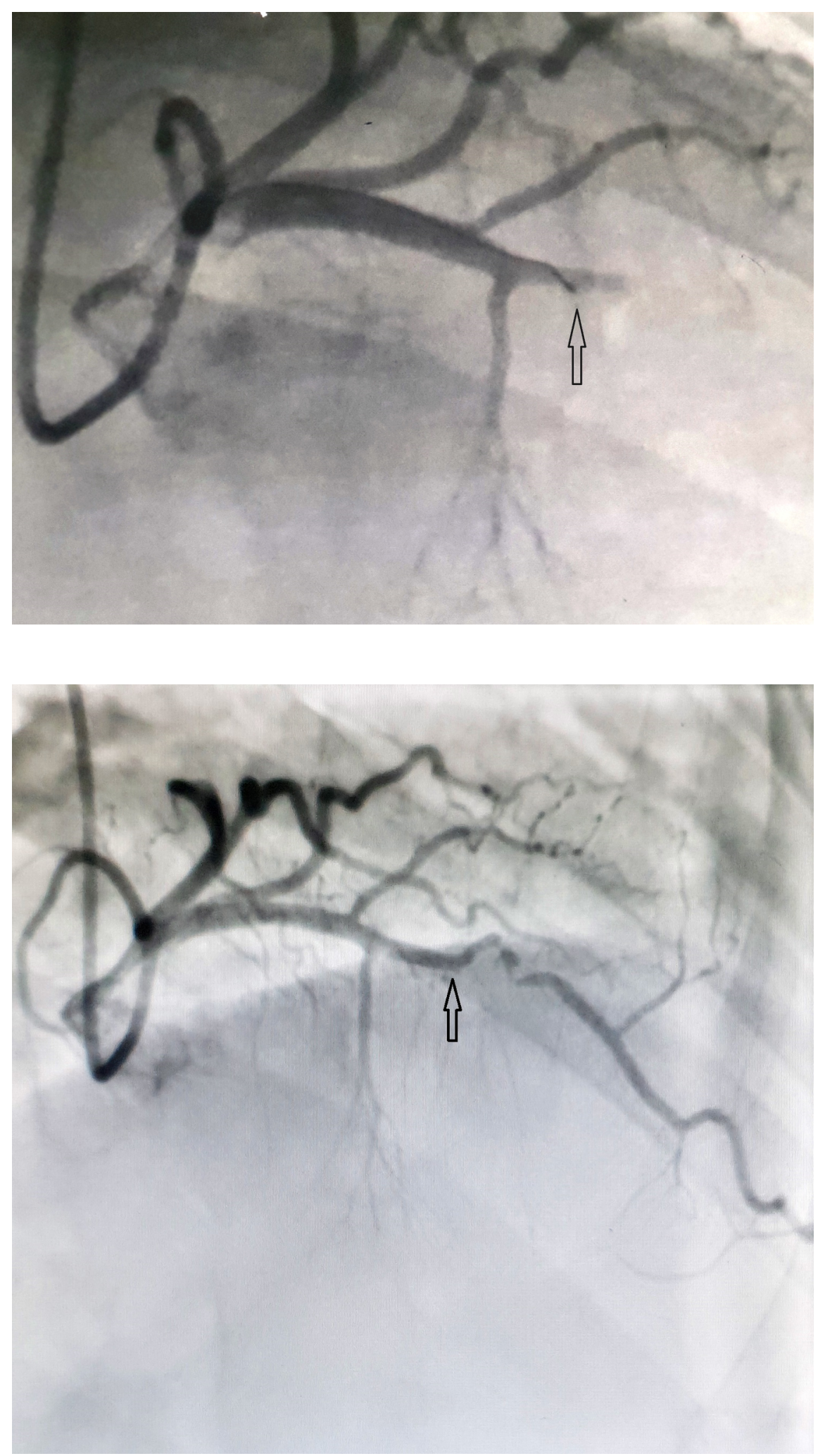